\title{
Short and easily scalable synthesis of the sex pheromone of the horse- chestnut leaf miner (Cameraria ohridella) relying on a key ligand- and additive-free iron-catalyzed cross-coupling.
}

\author{
Pablo Chourreu, ${ }^{\mathrm{a}, \mathrm{b}}$ Olivier Guerret, ${ }^{\mathrm{b}}$ Loïc Guillonneau, ${ }^{\mathrm{b}}$ Eric Gayon, ${ }^{* \mathrm{~b}}$ and Guillaume Lefèvre*a \\ ${ }^{a}$ Chimie ParisTech, PSL University, CNRS, Institute of Chemistry for Life and Health Sciences, CSB2D, 75005 Paris, \\ France; ${ }^{\text {b }}$ M2i Development, Bâtiment ChemStart’Up, Allée Le Corbusier, 64170 Lacq, France. \\ Supporting Information Placeholder
}

\begin{abstract}
We describe in this work a short 6-step convergent high-scale synthesis of the sex pheromone of the horse-chestnut leaf miner (8E,10Z-tetradeca-8,10-dienal). This procedure relies on a key stereoselective iron-catalyzed Kumada cross-coupling, which affords the coupling product with a high yield in the absence of additional ligands or additives. DFT calculations moreover suggest that $\omega$-alkoxide groups on iron-ligated chains in transient organoiron(II) intermediates can enhance their stability and hamper their decomposition in off-cycle $\beta$-hydride elimination reactions.
\end{abstract}

Keywords: pheromones, cross-coupling, iron catalysis, mechanisms

\section{INTRODUCTION}

Unlike the use of pesticides, which currently causes significant ecological issues, bio-control based on use of pheromones is an eco-friendly solution for the protection of a wide range of crops, vineyards, and plants. ${ }^{1 a}$ Moreover, pheromones are fully biodegradable, specific to the sole target species, and do not display toxicity to human health. ${ }^{\text {lb }}$ In our efforts to develop efficient and reliable high-scale synthetic procedures to access a large variety of chemicals of interest for biological control, we report herein a new convergent synthesis of the sex pheromone of horse-chestnut leaf miner (Cameraria ohridella, 8E,10Z-tetradeca-8,10-dienal, 1, Scheme 1). Significant damage is caused by this leaf-mining moth to horse chestnut trees in almost all countries of western Europe, especially during late summer time. During this period, larvae cause necrosis of the leaves, following by their shedding. In that context, protection of the trees can be achieved by an efficient control of the horse-chestnut leaf miner infestations by using the specific sex pheromone $\mathbf{1}$. This pheromone attracts, traps or sexually confuses males, interrupting the reproductive cycle of the leaf-miner. ${ }^{2}$

Several syntheses of $\mathbf{1}$ were reported in the past, relying mostly on the introduction of either $\mathrm{C}_{9}-\mathrm{C}_{10}$ or $\mathrm{C}_{10}-\mathrm{C}_{11}$ linkages as key steps (Scheme 1). Syntheses reported by $\operatorname{Svatos}^{2}$ (7 steps, $28 \%$ yield) and Grodner ${ }^{3}$ (9 steps, 12\% yield) relied on the introduction of the $\mathrm{C}_{9}-\mathrm{C}_{10}$ bond respectively by Sonogashira and Kumada cross-couplings between alkenyl iodides and pent1-yne or its Grignard. An 1,3-enyne is then obtained, and further reduction of the triple bond by dicyclohexylborane affords the expected conjugated diene. Grodner also reported an alternative strategy, relying on the introduction of the $\mathrm{C}_{9}-\mathrm{C}_{10}$ linkage by addition of the lithium acetylide salt of nonyn-8-ol
Scheme 1. Structure of the sex pheromone of the horsechestnut leaf miner (1) and reported synthetic strategies.

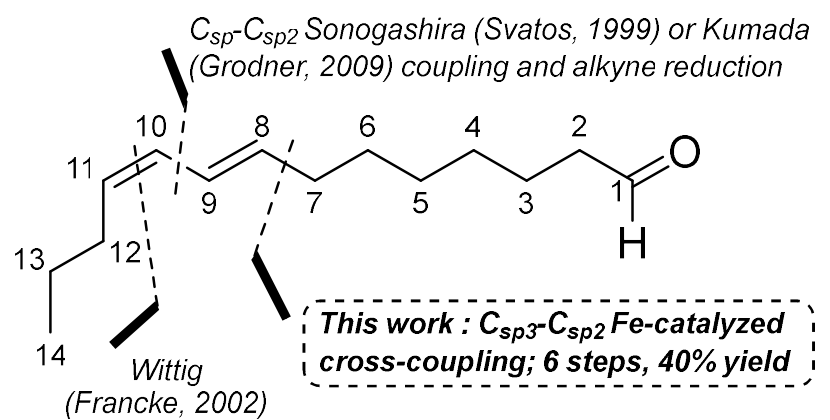

tetrahydropyranylether onto pentanal. The corresponding 1,3enyne is obtained after dehydration at $155-165{ }^{\circ} \mathrm{C}$ under reduced pressure $(40 \%$ yield, $10 Z / 10 E=81 / 19)$, and a reduction of the triple bond by $\mathrm{LiAlH}_{4}$ at high temperature affords the expected diene $(71 \%$ yield, $10 Z / 10 E=67 / 33)$. A last method described by Francke in 2002 relies on the construction of the $\mathrm{C}_{10}-\mathrm{C}_{11}$ linkage by a Wittig reaction involving an $\alpha, \beta$ unsaturated aldehyde. ${ }^{4}$ In that last example, the $\mathrm{C}_{9}-\mathrm{C}_{10}$ bond comes from the 2-propyne-1-ol used as a starting reagent. Therefore, all syntheses for pheromone 1 so far reported involve important step numbers and are for some of them linear procedures involving numerous steps with a low atom economy and expensive Pd-based catalysts. Moreover, they all rely on key acetylenic intermediates, which thus requires to handle highly reactive or volatile alkyne sources (such as lithium acetylide $^{2,3}$ ) to introduce and functionalize those species. This 
hampers application of these syntheses at high scales, making them unattractive for industrial eco-friendly purposes.

Inspired by our previous work ${ }^{5}$ on the synthesis of a similar dienic pheromone (sex pheromone of the European grapevine moth Lobesia botrana), we report herein a synthesis of pheromone 1 relying on the introduction of the $\mathrm{C}_{7}-\mathrm{C}_{8}$ linkage by a key alkyl-alkenyl Fe-catalyzed Kumada cross-coupling between a Grignard reagent and a dienol phosphate. This synthesis is a 6-step convergent procedure starting from the diethyl ester of pimelic acid (EtOOC- $\left(\mathrm{CH}_{2}\right)_{5}$-COOEt) and trans-hept-2-enal, which affords pheromone 1 with a $40 \%$ yield and a diastereomeric purity of $90 \%$. This method is moreover easily scalable, and allowed to prepare ca. $40 \mathrm{~g}$ of 1 , and the use of a cheap, eco-friendly and abundant transition metal such as iron as a catalyst of the key cross-coupling step is an appealing alternative to the use of noble metals. ${ }^{6}$ The synthetic strategy followed in this work is discussed thereafter. The reactivity of the organometallic species formed during the iron-catalyzed cross-coupling step is also discussed by means of DFT calculations in order to rationalize the selectivity of the coupling process.

\section{RESULTS AND DISCUSSION}

The synthetic strategy followed in this work is detailed in Scheme 2. This has been inspired by our previous work on synthesis of the sex pheromone of Lobesia botrana: we could indeed demonstrate that $\alpha, \omega$-magnesium alkoxide salts of Grignard reagents could be used as efficient nucleophiles in ligand- and additive-free iron-catalyzed cross-couplings with alkenyl electrophiles. ${ }^{5}$ Applying this strategy to the convergent synthesis of $\mathbf{1}$, the Grignard reagent of 7-magnesium alkoxide salt $\mathbf{5}$ is subjected to an iron-catalyzed Kumada cross-coupling with diastereomerically pure $(1 E, 3 Z)$-dienol phosphate 6a. Preparation of synthons $\mathbf{5}$ and $\mathbf{6 a}$ as well as the cross-coupling step are detailed thereafter.

Preparation of the $\mathbf{C}_{\mathbf{1}}-\mathbf{C}_{7}$ synthon (5). Diethyl pimelate $\mathbf{2}$ was chosen as a starting material for the construction of the $\mathrm{C}_{1}-\mathrm{C}_{7}$ chain (Scheme 2). Reduction of the diester $\mathbf{2}$ into the corresponding diol 3 (heptane-1,7-diol) was achieved using 3.0 equiv. of sodium bis(2-methoxyethoxy)aluminium hydride (Red-Al) in an almost quantitative yield (98\%). Monochloration of 3 leading to 7-chloroheptan-1-ol 4 was then performed using aqueous $\mathrm{HCl}(37 \mathrm{wt}-\%)$ as a chlorinating reagent in toluene (reflux conditions, $20 \mathrm{~h}$ ), adapting procedure reported by Chong for monobromination of $\alpha, \omega$-diols. ${ }^{7}$ During this step, formation of 1,7-dichloroheptane could be limited by carrying the chlorination at low diol concentrations $(0.15 \mathrm{M}$ in toluene), and 4 was obtained with a good $87 \%$ yield. Preparation of $\alpha, \omega$ magnesium alkoxide salt of Grignard reagent $\mathbf{5}$ was then performed from $\mathbf{4}$ according to our previously reported procedure. ${ }^{5}$ Addition of $\mathbf{4}$ onto a THF mixture containing insitu-synthesized $n$ - $\mathrm{BuMgCl}$ (1.0 equiv.) and $\mathrm{Mg}$ (1.1 equiv.) at $-10{ }^{\circ} \mathrm{C}$ led to formation of the corresponding magnesium alkoxide salt. Progressive heating at $70{ }^{\circ} \mathrm{C}$ allowed formation of the corresponding Grignard reagent 5 with an overall $90 \%$ yield. 5 was then directly subjected to react with $(1 E, 3 Z)$-dienol phosphate 6a in a one-pot strategy. Synthesis and purification of $\mathbf{6 a}$ is discussed in the following section.

Preparation of $(1 E, 3 Z)$-dienol phosphate 6a. Stereoselective preparation of dienol phosphates was described by Cahiez in 2008 starting from $\alpha, \beta$-unsaturated aldehydes. ${ }^{8}$ Dienol phosphate $\mathbf{6 a}$ was prepared by treatment of trans-hept-2-enal 8 with $t \mathrm{BuOK}$ at $-45{ }^{\circ} \mathrm{C}$ (Scheme 3 ), followed by addition of diethyl chlorophosphate. A mixture of $(1 E, 3 Z)$ and $(1 E, 3 E)$ dienol phosphates $\mathbf{6 a}$ and $\mathbf{6 b}$ (80\% yield, 70/30 ratio) was obtained.

Scheme 3. Preparation of diastereomerically pure $(1 E, 3 Z)$ dienol phosphate 6 a.

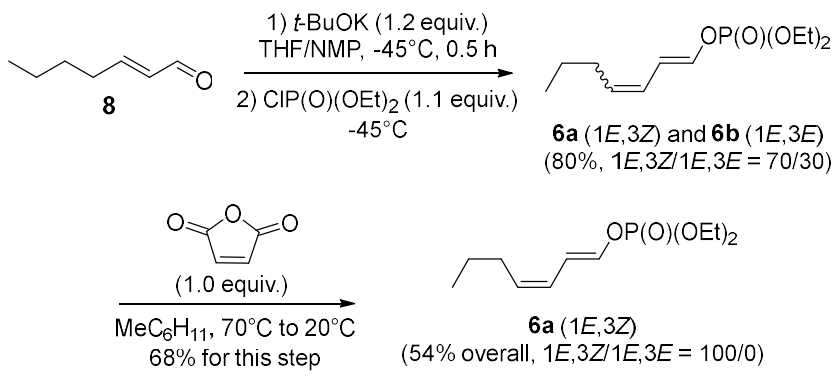

Separation of $\mathbf{6 a} / \mathbf{6 b}$ mixture by chromatography on silica gel is not easily carried out at high industrial scales. In order to circumvent this matter, $(1 E, 3 Z)$-dienol phosphate $6 \mathbf{a}$ and its

Scheme 2. Synthesis route toward pheromone 1 described in this work.

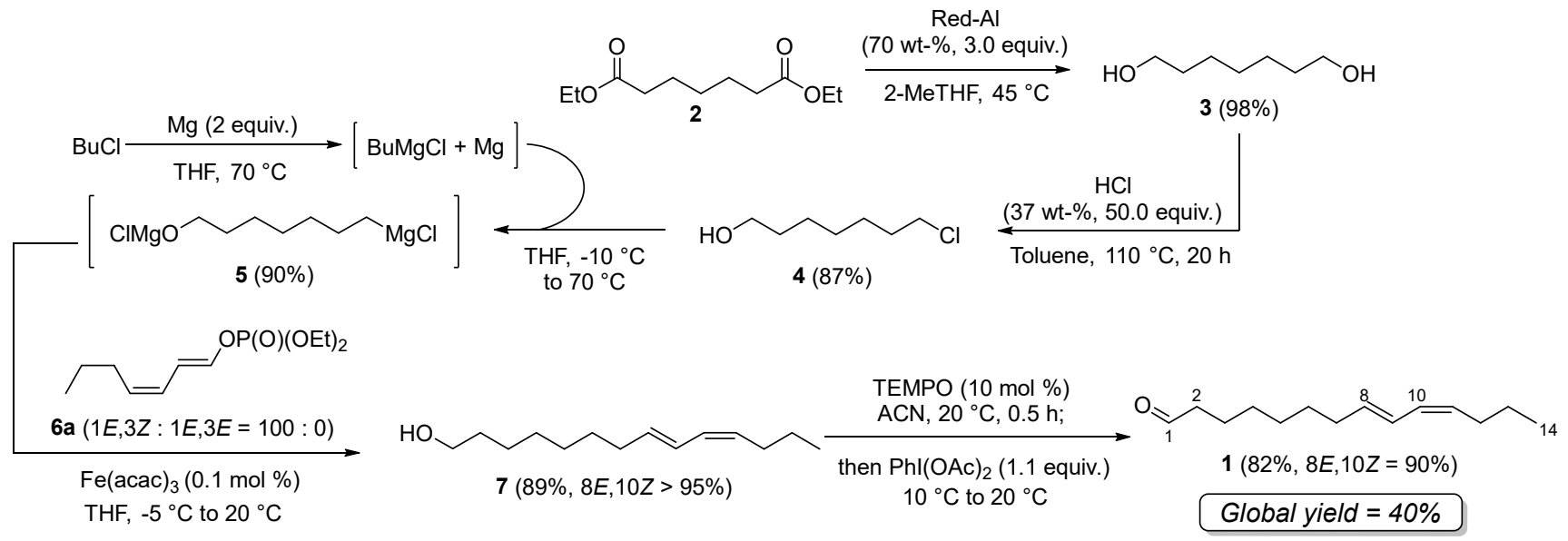


minor isomer $(1 E, 3 E)$ (6b) were conveniently separated by treating the $\mathbf{6 a} / \mathbf{6 b}$ mixture with 1.0 equiv. of maleic anhydride in methylcyclohexane. A Diels-Alder reaction selectively occurs between $\mathbf{6 b}$ and maleic anhydride, leading to the corresponding cycloaddition product. ${ }^{9}$ Precipitation of the latter allowed an easy purification of $\mathbf{6 a}$, obtained with an overall $54 \%$ yield from 8 and an excellent diastereomeric ratio $(1 E, 3 Z) /(1 E, 3 E)=100 / 0$. Diastereomerically pure $6 \mathbf{a}$ was then subjected to cross-coupling with $\mathbf{5}$ in an iron-catalyzed Kumada cross-coupling.

Iron-catalyzed cross-coupling between 5 and $6 \mathrm{a}$ and obtention of pheromone 1. Cross-coupling between 5 and $\mathbf{6 a}$ proceeded in one-pot conditions after obtention of $\omega$-alkoxide Grignard 5. Reaction medium was cooled down at $-5{ }^{\circ} \mathrm{C}$ and, after addition of $\mathrm{Fe}(\mathrm{acac})_{3}(0.001$ equiv.), dienol phosphate $\mathbf{6 a}$ was added dropwise. Due to the high viscosity of the bulk, the reaction medium was stirred overnight at $20{ }^{\circ} \mathrm{C}$ to ensure full consumption of $\mathbf{5}$. Cross-coupling product 7 was then obtained in a high $89 \%$ isolated yield. Moreover, this coupling is highly stereoselective since the expected isomer $(8 E, 10 Z)-7$ is obtained with a $95 \%$ diastereomeric purity. It is worth noting that the alkyl-alkenyl Fe-catalyzed Kumada cross-coupling between $\mathbf{5}$ and $\mathbf{6 a}$ remarkably proceeds without requiring additional ligands ${ }^{10 a}$ or any toxic additive such as $\mathrm{N}$ MethylPyrrolidinone (NMP), ${ }^{10 b-c}$ as usually required by classic procedures. Importantly, very small amount of Grignard $\beta$ elimination byproduct is observed $(<5 \%)$. Oxidation of 7 by iodobenzene diacetate $\left(\mathrm{PhI}(\mathrm{OAc})_{2}\right)$ in the presence of a catalytic amount of TEMPO finally affords pheromone 1 ( $82 \%$ yield) with a $90 \%$ diastereomeric purity. ${ }^{11}$

Overall, this procedure allows to achieve synthesis of pheromone 1 with a $40 \%$ yield and a $90 \%$ diastereomeric purity in a short 6-step synthesis from commercial diethyl pimelate $\mathbf{2}$ and trans-hept-2-enal 8. It is also worth mentioning that the 6-step procedure described in this work includes the 2step preparation of the $\alpha, \omega$-chloroalcohol 4 , its bromide analogue being used as a starting material in Svatos method. ${ }^{2}$ Our procedure allowed us to prepare a batch of ca. $40 \mathrm{~g}$ of pheromone $\mathbf{1}$, showing that this synthesis can easily be scaled up and is thus particularly appealing for industrial applications. After formulation of the pheromone, such an amount allows to treat an area of ca $80 \mathrm{~km}^{2}$.

Fe-catalyzed cross-couplings between alkyl nucleophiles and alkenyl electrophiles usually require additional ligands (e.g. NHeterocyclic Carbenes ${ }^{10 a}$ ) or additives (such as $\mathrm{NMP}^{10 \mathrm{~b}}$ ) to proceed with high yields. The mechanistic insights of those transformations still remain unclear, but it was recently demonstrated that homoleptic tris-coordinated ate organoiron(II) species $\left[\mathrm{R}_{3} \mathrm{Fe}^{\mathrm{II}}\right]^{-}$were formed by reduction of precursors such as $\mathrm{Fe}(\mathrm{acac})_{3}$ in the presence of an excess of alkyl Grignard reagents ( $\mathrm{RMgX}, \mathrm{R}=\mathrm{Me},{ }^{12 \mathrm{a}} \mathrm{Et}^{12 \mathrm{~b}}$ ). Alkyliron(II) species can be either key intermediates in the cross-coupling pathway, quickly lead to reduced iron polynuclear frameworks, ${ }^{12}$ or undergo decomposition by $\beta$-hydride elimination when the alkyl chain displays $\mathrm{H}$ atoms in $\beta$ position to the iron. ${ }^{13}$ The high yield obtained for cross-coupling between $\mathbf{5}$ and $\mathbf{6 a}$ in the absence of additional ligand or additive suggests that the transient organoiron(II) intermediates obtained during the catalytic cycle exhibit a good kinetic stability towards $\beta$-hydride elimination. This led us to investigate the

Scheme 4. Structures of tris- (a) and tetra-coordinated (b) isomers of $A$ (spin multiplicities superscripted and DFTcomputed energies in parenthesis (kcal.mol ${ }^{-1}$, PBE0-D3 / PCM THF level)); $M g=\operatorname{Mg}\left(\mathrm{OMe}_{2}\right)_{2}$.
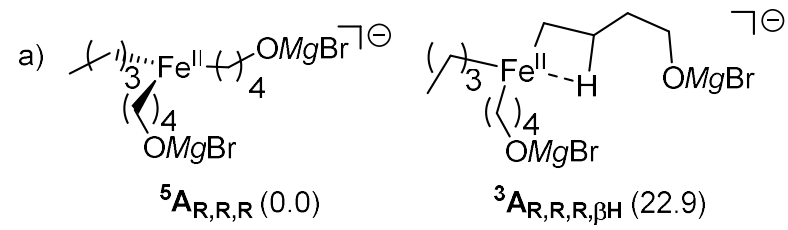

b)
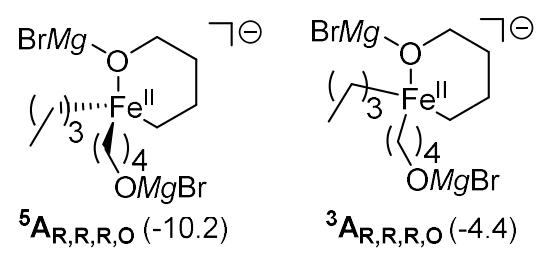

stability of the transmetallated species $\left[\mathrm{Fe}^{\mathrm{II}}\left(\left(\mathrm{CH}_{2}\right)_{7} \mathrm{OMgX}\right)_{3}\right]^{-}$ ( $\mathrm{X}=\mathrm{Br}$ or $\mathrm{Cl}$ ) by DFT computation.

In order to ensure a good compromise between accuracy and computation time, complex $\mathbf{A}\left(\left[\mathrm{Fe}^{\mathrm{II}}\left(\left(\mathrm{CH}_{2}\right)_{4} \mathrm{OMgBr}\right)_{2}(n-\mathrm{Bu})\right]^{-}\right)$ was first chosen as a model for $\left[\mathrm{Fe}^{\mathrm{II}}\left(\left(\mathrm{CH}_{2}\right)_{7} \mathrm{OMgX}\right)_{3}\right]^{-}$. A tetrahedral environment was chosen for $\mathrm{Mg}^{\mathrm{II}}$ cations (including explicit solvation by two $\mathrm{Me}_{2} \mathrm{O}$ molecules, chosen as a model for THF). Different isomers of A were computed, depending on their spin multiplicity and coordination number (Scheme 4). Tris-coordinated species ${ }^{\mathbf{5}} \mathbf{A}_{\mathbf{R}, \mathbf{R}, \mathbf{R}}$ (high-spin, $S=2$ ) and ${ }^{\mathbf{3}} \mathbf{A}_{\mathbf{R}, \mathbf{R}, \mathbf{R}, \mathbf{\beta H}}$ (intermediate spin, $S=1$ ) were found to be the two lowest energetic states with a coordination sphere involving the three $\sigma$-alkyl ligands and no chelation by $\omega$-alkoxide moieties (Scheme 4a).

The high-spin configuration was the most stable one, akin to numerous well-known ate- $\left[\mathrm{R}_{3} \mathrm{Fe}^{\mathrm{II}}\right]^{-}$species $\left(\mathrm{R}=\mathrm{Me},{ }^{12 \mathrm{a}} \mathrm{Et},{ }^{12 \mathrm{~b}}\right.$, Mes, ${ }^{14} \mathrm{Ph}^{15}$ ), lying $22.9 \mathrm{kcal}^{\mathrm{mol}}{ }^{-1}$ under its triplet analogue. Local $\mathrm{Fe}^{\mathrm{II}}$ environment in ${ }^{\mathbf{3}} \mathbf{A}_{\mathbf{R}, \mathbf{R}, \mathbf{R}, \boldsymbol{\beta H}}$ was square-planar, featuring the three coordinating $\sigma$-hydrocarbyl ligands, as well as an agostic interaction with one $\beta$-hydrogen. Feasibility of a $\beta$-agostic interaction is a prerequisite for the $\beta$-hydride elimination step. Such interaction requires the existence of vacant $d$ orbitals located on the metal, making possible the interaction of the latter with bonding $\sigma\left(\mathrm{C}_{\beta}-\mathrm{H}\right)$ orbitals. Since high-spin $\mathrm{Fe}^{\mathrm{II}}$ species $(S=2)$ do not have vacant $d$ orbitals, spin crossover to an intermediate multiplicity $\left(S=1\right.$ in $\left.{ }^{\mathbf{3}} \mathbf{A}_{\mathbf{R}, \mathbf{R}, \mathbf{R}, \mathbf{\beta H}}\right)$ must thus occur prior to the $\beta$-elimination process, in agreement with previously reports on $(\mathrm{P}, \mathrm{P})_{2} \mathrm{Fe}^{\mathrm{II}}(\mathrm{Et})_{2}$ systems. ${ }^{16}$

However, a more stable isomer of $\mathbf{A}$ can be obtained thanks to a coordination of one of the $\omega$-alkoxide moiety onto the $\mathrm{Fe}^{\mathrm{II}}$ ion, leading to a tetra-coordinated species with a high-spin ground state $\left({ }^{5} \mathbf{A}_{\mathbf{R}, \mathbf{R}, \mathbf{R}, \mathbf{O}}\right.$, stabilized by $10.2 \mathrm{kcal}^{\mathrm{mol}}{ }^{-1}$ with

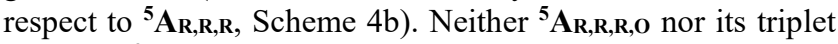
analogue ${ }^{3} \mathbf{A}_{\mathbf{R}, \mathbf{R}, \mathbf{R}, \mathbf{O}}$ can provide the requested $\beta$-agostic bond to initiate the $\beta$-hydride elimination process. Therefore, the energetic span required to ensure such a $\beta$-agostic interaction can be evaluated at $33.1 \mathrm{kcal}^{\mathrm{mol}}{ }^{-1}$ : this corresponds to the energy difference between quaternized species ${ }^{\mathbf{5}} \mathbf{A}_{\mathbf{R}, \mathbf{R}, \mathbf{R}, \mathbf{O}}$ and

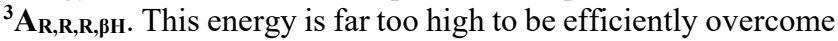
in the coupling conditions $\left(-5^{\circ} \mathrm{C}\right.$ to $\left.20^{\circ} \mathrm{C}\right)$, making unlikely the formation of the $\beta$-agostic bond. It can thus be drawn from those calculations that chelation of the $\mathrm{Fe}^{\mathrm{II}}$ ion by $\omega$-alkoxide moieties 
in in-situ formed tris-alkyl ate species can hamper the feasibility of $\beta$-agostic bonds. However, for $\omega$-alkoxide Grignard reagents with alkyl chains longer than those in model A (such as $\mathbf{5}$ in the present work), formation of a large metallacycle involving a $\mathrm{Fe}^{\mathrm{II}}-\mathrm{O}$ ligation might not be favored due to the high flexibility of the former. Indeed, in the case of $\mathbf{5}$, a 9 -member metallacycle is formed, and was found to be slightly less stable than $\mathbf{5}$ by $2.2 \mathrm{kcal}^{\mathrm{mol}} \mathrm{m}^{-1}\left({ }^{\mathbf{5}} \mathbf{B}_{\mathbf{R}, \mathbf{R}, \mathbf{R}, \mathbf{O}}\right.$ see SI). In that case, an intermolecular ligation of a tris-coordinated ate$\mathrm{Fe}^{\mathrm{II}}$ species by the alkoxide moiety of an additional equivalent of $\mathbf{5}$ can occur, consistently with the beneficial effect of magnesium alkoxide salts used as additives observed on alkylalkenyl Fe-catalyzed cross-coupling, as recently reported by some of us. ${ }^{17}$ Intra- or intermolecular stabilization of transient iron(II) intermediates by alkoxide moieties can thus prevent the evolution of those species toward $\beta$-hydride elimination pathway, which can account for the good conversion of the Grignard reagent in the cross-coupling between 5 and $\mathbf{6 a}$. This result echoes a recent report by Neidig, who demonstrated that transmetallation of Grignard reagents bearing $\omega$-acetal groups onto NHC-ligated $\mathrm{Fe}^{\mathrm{II}}$ species leads to an improved stability of the alkyliron(II) intermediates toward $\beta$-hydride elimination. ${ }^{18}$ In-depth mechanistic studies are under progress in order to understand the accurate role of the $\omega$-magnesium alkoxide functionalities in the cross-coupling sequence, as well as to investigate the ability of the tris-alkyliron(II) complex $\left[\mathrm{Fe}^{\mathrm{II}}\left(\left(\mathrm{CH}_{2}\right)_{7} \mathrm{OMgX}\right)_{3}\right]^{-}$to be involved as an on-cycle species in the coupling.

In summary, we have reported a new and easily scalable synthesis of the sex pheromone of the horse-chestnut leaf miner (8E,10Z-tetradeca-8,10-dienal). Our strategy relies on the introduction of the $\mathrm{C}_{7}-\mathrm{C}_{8}$ linkage by a key additive-free $\mathrm{Fe}$ catalyzed Kumada cross-coupling between a $\alpha, \omega$-magnesium alkoxide Grignard reagent and a diastereomerically pure (1E,3Z)-dienol phosphate. Presence of $\omega$-alkoxide groups on the lateral chains of the transmetallated alkyliron(II) intermediates moreover enhances the stability of those species toward $\beta$-hydride elimination, ensuring their good conversion in the cross-coupling process in the absence of additional ligands or of the usual additives.

\section{EXPERIMENTAL SECTION}

Gas chromatography analyses (GC) and mass spectra were performed on a Hewlett-Packart HP 5973 mass spectrometer via a GC/MS coupling with a Hewlett-Packart HP 6890 chromatograph equipped with a capillary column HP-5MS (50 m x $0.25 \mathrm{~mm} \times 0.25$ $\mu \mathrm{m} .5 \%$ polysilarylene / $95 \%$ polydimethylsiloxane). Ionisation was performed by electronic impact (EI, $70 \mathrm{eV}$ ). Mass spectra are reported as $\mathrm{m} / \mathrm{z}$ (molecular ion peak, \% of relative intensity). Helium was used as a carrier gaz $(1.0 \mathrm{~mL} / \mathrm{min}$, ratio split: 100). Standard analysis conditions: $40^{\circ} \mathrm{C}$ (hold $1 \mathrm{~min}$ ) to $250^{\circ} \mathrm{C}$ (hold 10 min), heating rate: $20^{\circ} \mathrm{C} / \mathrm{min}$. Standard flash column chromatography was performed on silica gel $60 .{ }^{1} \mathrm{H}$ NMR (400 $\left.\left.\mathrm{MHz}, \mathrm{CDCl}_{3}\right),{ }^{13} \mathrm{C} \mathrm{NMR} \mathrm{(100} \mathrm{MHz}, \mathrm{CDCl}_{3}\right)$ were recorded on a Brucker Avance III HD 400 instrument. Chemical shifts $(\delta)$ are given in ppm from TMS $\left({ }^{1} \mathrm{H},{ }^{13} \mathrm{C}\right)$. Coupling constants $(\mathrm{J})$ are given in $\mathrm{Hz}$. The following abbreviations are used: s (singlet), d (doublet), $\mathrm{t}$ (triplet), q (quartet), $\mathrm{m}$ (multiplet). All reagents and solvents were obtained from either Sigma-Aldrich, Acros, Alfa, VWR, or TCI and were used as received unless otherwise stated. High purity $\mathrm{Fe}(\mathrm{acac})_{3}(>99 \%)$ from Sigma-Aldrich was used. Dry solvents were obtained from commercial sources. All reactions were conducted in dry flasks under argon atmosphere. Titration of Grignard reagents was performed according to the procedure reported by Watson ${ }^{19}$ by using a $1 \mathrm{M}$ solution of sec-butyl alcohol in toluene, $1 \mathrm{~mL}$ of the THF solution of the Grignard reagent, and 1-2 $\mathrm{mg}$ of 2,2-biquinoline.

DFT calculations were carried out using the Gaussian09 v. D.01 code. Theory level: PBE0-D3 / 6-31+G* (C, H, Mg, O), 6-311G $(\mathrm{Br}), \mathrm{SDD}$ and associated pseudopotential $(\mathrm{Fe})$, solvation model: PCM-THF. See SI for the corresponding references.

Diethyl (hepta-1,3-dien-1-yl)-phosphate $((1 E, 3 Z)-6 a$ and $(1 E, 3 E)-6 b$ mixture). In a dry four-neck $2 \mathrm{~L}$ round-bottom flask equipped with a mechanical stirrer, a thermometer, and an argon inlet were introduced, at $20^{\circ} \mathrm{C}$, potassium tert-butoxide $(61.7 \mathrm{~g}, 535$ mmol, 1.2 eq.), THF (450 mL), and NMP (300 mL). The mixture was stirred at $-45^{\circ} \mathrm{C}$ using a cold finger in an ethanol bath and transheptenal (50.0 g, $446 \mathrm{mmol}, 1$ eq.) was added dropwise in $30 \mathrm{~min}$. $30 \mathrm{~min}$ after the end of the addition, diethyl chlorophosphate $(85.6$ $\mathrm{g}, 491 \mathrm{mmol}, 1.1$ eq.) was added dropwise in $1 \mathrm{~h}$ at $-45^{\circ} \mathrm{C}$. The mixture was stirred for $1 \mathrm{~h}$, and then quenched by adding $500 \mathrm{~mL}$ of distilled water at $5^{\circ} \mathrm{C}$. After 45 min under stirring at $20^{\circ} \mathrm{C}$, the aqueous layer was extracted with $3 \times 250 \mathrm{~mL}$ of methyl tert-butyl ether (MTBE). The combined organic layers were washed with $3 \mathrm{x}$ $250 \mathrm{~mL}$ of distilled water and concentrated under vacuum. The crude product was purified by chromatography on a silica gel column using heptane/EtOAc 9:1 as eluent to afford $88.6 \mathrm{~g}(80 \%)$ of an orange liquid $(1 E, 3 Z / 1 E, 3 E=70 / 30)$. GC: $t_{\mathrm{R}}(1 E, 3 Z)=8.83$ $\min , \operatorname{tr}(1 E, 3 E)=8.94 \mathrm{~min}$. MS (EI) $\mathrm{m} / \mathrm{z}:[\mathrm{M}]+=248.1$.

Diethyl ((1E,3Z)-hepta-1,3-dien-1-yl)-phosphate (6a). In a dry four-neck $2 \mathrm{~L}$ round-bottom flask equipped with a mechanical stirrer, a thermometer, a condenser, and an argon inlet were introduced the mixture of isomers $6 \mathbf{a}$ and $\mathbf{6 b}(310 \mathrm{~g}, 1.25 \mathrm{~mol}, 1$ eq., 70/30), maleic anhydride (122 g, $1.25 \mathrm{~mol}, 1$ eq.) and methylcyclohexane $(1 \mathrm{~L})$. The mixture was stirred at $70^{\circ} \mathrm{C}$ for $3 \mathrm{~h}$ then stirred at $20^{\circ} \mathrm{C}$ overnight. $1 \mathrm{~L}$ of an aqueous solution of $\mathrm{NaOH}(3 \mathrm{M})$ was added to the reaction mixture at $40^{\circ} \mathrm{C}$ to reach a $\mathrm{pH}$ of 14 . After decantation, the aqueous layer was extracted with $2 \times 600 \mathrm{~mL}$ of heptane. The combined organic layers were washed with $2 \times 600$ $\mathrm{mL}$ of a saturated $\mathrm{NaCl}$ aqueous solution and concentrated under vacuum. The resulting crude was dissolved in $200 \mathrm{~mL}$ of MTBE, filtrated and concentrated under vacuum again to afford $210.1 \mathrm{~g}$ $(68 \%)$ of an orange liquid $(1 E, 3 Z / 1 E, 3 E=100 / 0)$. GC: $\operatorname{tr}_{\mathrm{R}}(1 E, 3 Z)$ $=8.83 \mathrm{~min} .{ }^{1} \mathrm{H} \mathrm{NMR}\left(\mathrm{CDCl}_{3}, 400 \mathrm{MHz}\right) \delta 6.67(\mathrm{dd}, J=11.8,6.1$ $\mathrm{Hz}, 1 \mathrm{H}), 6.29$ (t, $J=11.7 \mathrm{~Hz}, 1 \mathrm{H}), 5.86(\mathrm{t}, J=11.2 \mathrm{~Hz}, 1 \mathrm{H}), 5.44$ $(\mathrm{dt}, J=10.8,7.6 \mathrm{~Hz}, 1 \mathrm{H}), 4.21-4.14(\mathrm{~m}, 4 \mathrm{H}), 2.12-2.06(\mathrm{~m}, 2 \mathrm{H})$, $1.43-1.38(\mathrm{~m}, 2 \mathrm{H}), 1.36(\mathrm{t}, J=7.1,6 \mathrm{H}), 0.90(\mathrm{t}, J=7.4 \mathrm{~Hz}, 3 \mathrm{H})$. ${ }^{13} \mathrm{C} \mathrm{NMR}\left(\mathrm{CDCl}_{3}, 100 \mathrm{MHz}\right) \delta 139.3,132.4,122.3,113.6,64.7$, 64.6, 29.9, 22.8, 16.3, 16.2, 13.9. MS (EI) m/z: [M]+=248.1.

Heptane-1,7-diol (3). In a dry four-neck $2 \mathrm{~L}$ round-bottom flask equipped with a mechanical stirrer, a thermometer, a condenser, and an argon inlet were introduced diethyl pimelate (100 g, 462 mmol, 1 eq.) and 2-MeTHF (500 mL). The solution was stirred at $45^{\circ} \mathrm{C}$ and a sodium bis(2-methoxyethoxy)aluminum hydride solution (Red-Al 70 wt-\%) (400 g, 1.39 mol, 3 eq.) was added dropwise in $2 \mathrm{~h}$. The mixture was stirred for $3 \mathrm{~h}$ at $45^{\circ} \mathrm{C}$, and then very carefully quenched by adding dropwise $600 \mathrm{~mL}$ of an aqueous solution of $\mathrm{HCl}(18 \%)$. After decantation, still at $45^{\circ} \mathrm{C}$, the aqueous layer was extracted with $3 \times 150 \mathrm{~mL}$ of methyl-THF. The combined organic layers were concentrated under vacuum. The resulting mixture was purified by distillation under reduced pressure $\left(60^{\circ} \mathrm{C}\right.$; 20 mbar) to remove methoxyethanol from $\mathrm{Re}-\mathrm{Al}$ quench, and to obtain $60.1 \mathrm{~g}(98 \%)$ of a slightly yellow liquid. GC: $\mathrm{t}_{\mathrm{R}}=6.94 \mathrm{~min}$. ${ }^{1} \mathrm{H} \mathrm{NMR}\left(\mathrm{CDCl}_{3}, 400 \mathrm{MHz}\right) \delta 3.63(\mathrm{t}, J=6.6 \mathrm{~Hz}, 4 \mathrm{H}), 1.58-1.52$ $(\mathrm{m}, 4 \mathrm{H}), 1.41-1.31(\mathrm{~m}, 6 \mathrm{H}) \cdot{ }^{13} \mathrm{C} \mathrm{NMR}\left(\mathrm{CDCl}_{3}, 100 \mathrm{MHz}\right) \delta 62.9$ (2C), 32.7 (2C), 29.2 (2C), 25.7. MS (EI) m/z: [M]+ = 132.0. 
7-chloroheptan-1-ol (4). In a dry four-neck $4 \mathrm{~L}$ round-bottom flask equipped with a mechanical stirrer, a thermometer, a condenser, and an argon inlet were introduced heptane-1,7-diol 3 $(40 \mathrm{~g}, 302.5 \mathrm{mmol}, 1$ eq.) and toluene $(1 \mathrm{~L})$. The solution is vigorously stirred and a $37 \% \mathrm{HCl}$ aqueous solution $(1.25 \mathrm{~L}, 15.13$ mol, 50 eq.) is progressively added to the reaction mixture. After stirring the reaction at $110^{\circ} \mathrm{C}$ for $20 \mathrm{~h}$, the organic layer is separated from the aqueous one, which is extracted with $3 \times 200 \mathrm{~mL}$ of toluene. The combined organic layers were washed with $2 \times 200$ $\mathrm{mL}$ of saturated $\mathrm{NaHCO}_{3}$ aqueous solution and with $200 \mathrm{~mL}$ of distilled water, dried over magnesium sulphate, filtrated and concentrated under vacuum. The resulting product was purified by chromatography on a silica gel column using heptane/EtOAc 7:3 as eluent to obtain $39.4 \mathrm{~g}(87 \%)$ of a slightly yellow liquid. GC: $\mathrm{t}_{\mathrm{R}}=$ $6.42 \mathrm{~min} .{ }^{1} \mathrm{H} \mathrm{NMR}\left(\mathrm{CDCl}_{3}, 400 \mathrm{MHz}\right) \delta 3.65(\mathrm{t}, J=6.6 \mathrm{~Hz}, 2 \mathrm{H})$, $3.53(\mathrm{t}, J=6.7 \mathrm{~Hz}, 2 \mathrm{H}), 1.83-1.72(\mathrm{~m}, 2 \mathrm{H}), 1.62-1.53(\mathrm{~m}, 2 \mathrm{H})$, $1.49-1.41(\mathrm{~m}, 2 \mathrm{H}), 1.41-1.33(\mathrm{~m}, 4 \mathrm{H}) .{ }^{13} \mathrm{C} \mathrm{NMR}\left(\mathrm{CDCl}_{3}, 100\right.$ $\mathrm{MHz}) \delta 63.0,45.1,32.7,32.5,28.7,26.8,25.6 . \mathrm{MS}(\mathrm{EI}) \mathrm{m} / \mathrm{z}:[\mathrm{M}]+$ $=150.0$.

Grignard reagent 5 prepared from 7-chloroheptan-1-ol (4). In a dry four-neck $2 \mathrm{~L}$ round-bottom flask equipped with a mechanical stirrer, a thermometer, a condenser, and an argon inlet were introduced magnesium $(17 \mathrm{~g}, 697 \mathrm{mmol}, 2.10$ eq.) and THF $(63 \mathrm{~mL})$. Ethyl bromide ( $1.5 \mathrm{~g}, 13.5 \mathrm{mmol}, 0.04$ eq.) was added instantaneously under vigorous stirring and the reaction mixture was then stirred at $50^{\circ} \mathrm{C}$. A solution of $n$-butyl chloride $(32.3 \mathrm{~g}, 349$ mmol, 1.05 eq.) in THF ( $249 \mathrm{~mL})$ was added dropwise in $2 \mathrm{~h}$ and, after the end of the addition, the mixture was stirred $3 \mathrm{~h}$ under reflux. The reaction mixture was cooled to $-10^{\circ} \mathrm{C}$ and $7-$ chloroheptan-1-ol 4 (50 g, $332 \mathrm{mmol}, 1$ eq.) was added dropwise in $30 \mathrm{~min}$. The cooling bath was removed and the reaction mixture was stirred for $30 \mathrm{~min}$ at $20^{\circ} \mathrm{C}$ then overnight under reflux. After cooling to room temperature, the expected Grignard reagent $\mathrm{ClMgO}\left(\mathrm{CH}_{2}\right)_{7} \mathrm{MgCl} 5$ was obtained with a $90 \%$ yield.

(8E,10Z)-tetradeca-8,10-dien-1-ol (7). To 299 mmol (1.0 eq.) of $\mathrm{ClMgO}\left(\mathrm{CH}_{2}\right)_{7} \mathrm{MgCl}$ prepared as described before were added THF $(402 \mathrm{~mL})$ and, at $-5^{\circ} \mathrm{C}$, iron(III) acetylacetonate (106 mg, 0.30 mmol, 0.001 eq.) in one portion. To the dark mixture thus obtained, diethyl ((1E,3Z)-hepta-1,3-dien-1-yl) phosphate 6a (83 g, 332 $\mathrm{mmol}, 1.1$ eq.) was added dropwise in $50 \mathrm{~min}$. The reaction mixture was then stirred at $20^{\circ} \mathrm{C}$ overnight. The mixture was cooled to $5^{\circ} \mathrm{C}$ and quenched adding progressively $500 \mathrm{~mL}$ of an aqueous solution of $\mathrm{HCl}(2 \mathrm{M})$. After decantation, the aqueous layer was extracted with $3 \times 250 \mathrm{~mL}$ of MTBE. The combined organic layers were washed with $2 \times 500 \mathrm{~mL}$ of distilled water and concentrated under vacuum. The resulting product was purified by chromatography on a silica gel column using heptane/EtOAc 9:1 as eluent to obtain $56.0 \mathrm{~g}(89 \%)$ of an orange oil. $(8 E, 10 Z / 8 E, 10 E=98.5 / 1.5)$. GC: $\mathrm{t}_{\mathrm{R}}(8 E, 10 Z)=9.34 \mathrm{~min}, \mathrm{t}_{\mathrm{R}}(8 E, 10 Z)=9.39 \mathrm{~min} .{ }^{1} \mathrm{H} \mathrm{NMR}\left(\mathrm{CDCl}_{3}\right.$, $400 \mathrm{MHz}) \delta 6.30(\mathrm{ddd}, J=15.1,11.0,1.1 \mathrm{~Hz}, 1 \mathrm{H}), 5.96(\mathrm{t}, J=10.9$ $\mathrm{Hz}, 1 \mathrm{H}), 5.71-5.58(\mathrm{~m}, 1 \mathrm{H}), 5.31(\mathrm{dt}, J=10.7,7.6 \mathrm{~Hz}, 1 \mathrm{H}), 3.64$ $(\mathrm{t}, J=6.6 \mathrm{~Hz}, 2 \mathrm{H}), 2.20-2.04(\mathrm{~m}, 4 \mathrm{H}), 1.60-1.53(\mathrm{~m}, 2 \mathrm{H}), 1.45$ -1.38 (m, 4H), $1.38-1.26(\mathrm{~m}, 6 \mathrm{H}), 0.92(\mathrm{t}, J=7.4 \mathrm{~Hz}, 3 \mathrm{H}) .{ }^{13} \mathrm{C}$ NMR $\left(\mathrm{CDCl}_{3}, 100 \mathrm{MHz}\right) \delta 134.8,130.1,128.9,125.9,63.3,33.0$, $33.0,29.9,29.5,29.5,29.4,25.9,23.1,14.0 . \mathrm{MS}(\mathrm{EI}) \mathrm{m} / \mathrm{z}:[\mathrm{M}]+=$ 210.2 .

(8E,10Z)-tetradeca-8,10-dienal (1). In a dry four-neck $1 \mathrm{~L}$ round-bottom flask equipped with magnetic stirring, a thermometer, a condenser, and an argon inlet were introduced compound 7 (51 g, $242 \mathrm{mmol}, 1$ eq.), acetonitrile $(255 \mathrm{~mL})$ and TEMPO (3.8 g, $24.2 \mathrm{mmol}, 0.1 \mathrm{eq})$. The mixture was stirring for $30 \mathrm{~min}$ at $20^{\circ} \mathrm{C}$ then cooled to $10^{\circ} \mathrm{C}$. Once at this temperature, (diacetoxyiodo)benzene ( $85.6 \mathrm{~g}, 266 \mathrm{mmol}, 1.1 \mathrm{eq}$.$) was$ progressively added then the reaction mixture was stirred for $2 \mathrm{~h}$ at $20^{\circ} \mathrm{C}$. $250 \mathrm{~mL}$ of a saturated sodium thiosulfate aqueous solution were added to quench the reaction. After decantation, the aqueous layer was extracted with $2 \times 200 \mathrm{~mL}$ of AcOEt. The combined organic layers were washed with $3 \times 200 \mathrm{~mL}$ of a saturated $\mathrm{NaHCO}_{3}$ aqueous solution and concentrated under vacuum. The crude product was purified by chromatography on a silica gel column using heptane/EtOAc 9:1 as eluent to afford $41.3 \mathrm{~g}(82 \%)$ of a yellow oil. $(8 E, 10 Z / 8 E, 10 E / 8 Z, 10 E / 8 Z, 10 Z=$ $90.5 / 4.5 / 3.5 / 1.5)$. GC: $t_{R}(8 Z, 10 Z)=8.90 \mathrm{~min}, \mathrm{t}_{\mathrm{R}}(8 E, 10 Z)=8.99$ min, $\mathrm{t}_{\mathrm{R}}(8 Z, 10 E)=9.03 \mathrm{~min}, \mathrm{t}_{\mathrm{R}}(8 E, 10 E)=9.05 \mathrm{~min} .{ }^{1} \mathrm{H} \mathrm{NMR}$ $\left(\mathrm{CDCl}_{3}, 400 \mathrm{MHz}\right) \delta 9.76(\mathrm{t}, J=1.8 \mathrm{~Hz}, 1 \mathrm{H}, \mathrm{H} 1), 6.30(\mathrm{ddd}, J=$ $14.8,10.8,1.2 \mathrm{~Hz}, 1 \mathrm{H}, \mathrm{H} 9), 5.95$ (dd, $J=10.9,10.9 \mathrm{~Hz}, 1 \mathrm{H}, \mathrm{H} 10$ ), $5.67-5.60$ (m, 1H, H8), 5.29 (dt, $J=10.8,7.6 \mathrm{~Hz}, 1 \mathrm{H}, \mathrm{H} 11), 2.42$ (dt, $J=7.4,1.8 \mathrm{~Hz}, 2 \mathrm{H}, \mathrm{H} 2), 2.16-2.06$ (m, 4H, H7, H12), $1.67-$ $1.58(\mathrm{~m}, 2 \mathrm{H}, \mathrm{H} 3), 1.44-1.30$ (m, 8H, H4, H5, H6, H13), $0.91(\mathrm{t}, J$ $=7.4 \mathrm{~Hz}, 3 \mathrm{H}, \mathrm{H} 14) .{ }^{13} \mathrm{C} \mathrm{NMR}\left(\mathrm{CDCl}_{3}, 100 \mathrm{MHz}\right) \delta 203.0,134.5$, 130.2, 128.9, 126.0, 44.1, 32.9, 29.9, 29.3, 29.2, 29.1, 23.1, 22.2, 14.0. MS (EI) $\mathrm{m} / \mathrm{z}:[\mathrm{M}]+=208.2$. All analytical data match those previously reported by Grodner ${ }^{3}$ and Francke and coworkers ${ }^{4}$.

\section{ASSOCIATED CONTENT}

\section{Supporting Information}

The Supporting Information is available free of charge on the ACS Publications website. The SI PDF file contents ${ }^{1} \mathrm{H}$ and ${ }^{13} \mathrm{C}$ NMR spectra of compounds discussed in this work, as well as Cartesian coordinates and energetic features of DFT-calculated structures.

\section{AUTHOR INFORMATION}

\section{Corresponding Author}

* E-mail : guillaume.lefevre@chimieparistech.psl.eu

* E-mail : eric.gayon@m2i-development.com

The authors declare no competing financial interest.

\section{ACKNOWLEDGMENT}

The M2i company is thanked for its financial support (CIFRE grant program for P. C.) in the frame of the M2i-CNRS joint research program "PheroChem". Sophie Mendès, Daniel Guyot and Nicolas Lefèvre (M2i company) are thanked for their contributions.

\section{REFERENCES}

(1) a) Witzgall, P.; Kirsch, P.; Cork, A. Sex Pheromones and their Impact on Pest Management. J. Chem. Ecol. 2010, 36, 80-100; b) Kirsch, P. Pheromones: their Potential Role in the Control of Agricultural Insect Pests. Am. J. Altern. Agric. 1988, 3, 83-97. (2) a) Svatos, A.; Kalinova, B.; Hoskovec, M.; Kindl, J.; Hovorka, O.; Hrdy, I. Identification of a New Lepidopteran Sex Pheromone in Picogram Quantities using an Antennal Biodetector: (8E,10Z)tetradeca-8,10-dienal from Cameraria ohridella. Tet. Lett. 1999, 40, 7011-7014; b) Svatos, A.; Kalinova, B.; Hoskovec, M.; Kindl, J.; Hrdy. Tetradeca-8,10-dienals, the Method of Preparation thereof and their Use as Sexual Attractants for Leafminer Moths. European Patent EP1192117A1, 2001.

(3) Grodner, J. An Alternative Synthesis of (8E,10Z)-Tetradeca8,10-dienal, Sex Pheromone of Horse-Chestnut Leafminer (Cameraria ohridella). Tetrahedron 2009, 65, 1648-1654.

(4) Francke, W.; Franke, S.; Bergmann, J.; Tolasch, T.; Subchev, M.; Mircheva, A.; Toshova, T.; Svatos, A.; Kalinova, B.; Karpati, Z.; Szöcs, G.; Toth, M. Female Sex Pheromone of Cameraria ohridella Desch. and Dim. (Lepidoptera: Gracillariidae): Structure Confirmation, Synthesis and Biological Activity of (8E,10Z)-8,10Tetradecadienal and some Analogues. Z. fur Naturforsch. 2002, C $57,739-752$. In that work, minor isomer $(E, E)$ obtained after Wittig 
reaction was removed by Diels-Alder reaction with tetracyanoethylene.

(5) a) Cahiez, G.; Guerret, O.; Moyeux, A.; Dufour, S.; Lefèvre, N. Eco-Friendly and Industrially Scalable Synthesis of the Sex Pheromone of Lobesia Botrana. Important Progress for the Eco-Protection of Vineyard. Org. Process Res. Dev. 2017, 21, 1542-1546; b) Nouveau Procédé de Fabrication du (E,Z)-7,9-Dodécadiényl-1-acétate, S. Dufour, O. Guerret, WO 2016/001383 A1.

(6) for a recent review on Fe-catalyzed cross-coupling, see section 2.4 in Bauer, I.; Knölker, H.-J. Iron Catalysis in Organic Synthesis. Chem. Rev. 2015, 115, 3170-3387.

(7) Chong, J. M.; Heuft, M. A.; Rabbat, P. Solvent Effects on the Monobromination of $\alpha, \omega$-Diols: A Convenient Preparation of $\omega$ Bromoalkanols. J. Org. Chem. 2000, 65, 5837-5838.

(8) Cahiez, G.; Habiak, V.; Gager, O. Stereoselective Preparation of Dienol Phosphates from $\alpha, \beta$-Ethylenic Aldehydes. J. Org. Chem. 2008, 73, 6871-6872.

(9) Pucheault, M.; Liautard, V.; Guillonneau, L.; Guerret, O. Nouvelle Composition d'Isomères du 7,9-Dodécadiényl-1-acétate et son Procédé de Fabrication ; French Patent FR 3063729.

(10) a) for an exemple of alkyl-alkyl Fe-catalyzed cross-coupling involving NHC-stabilized species, see: Guisán-Ceinos, M.; Tato, F.; Buñuel, E.; Calle, P.; Cárdenas, D.J. Fe-Catalysed Kumada-type Alkyl-Alkyl Cross-Coupling. Evidence for the Intermediacy of Fe(I) Complexes. Chem. Sci. 2013, 4, 1098-1104; b) Cahiez, G.; Avedissian, H. Highly Stereo- and Chemoselective Iron-Catalyzed Alkenylation of Organomagnesium Compounds. Synthesis 1998, 1199-1205; c) Reprotoxic Category 2, R61, Official Journal of the European Union, December 31, 2008, European regulation No 1272/2008.

(11) De Mico, A.; Margarita, R.; Parlanti, L.; Vescovi, A.; Piancatelli, G. A Versatile and Highly Selective Hypervalent Iodine (III)/2,2,6,6Tetramethyl-1-piperidinyloxyl-Mediated Oxidation of Alcohols to Carbonyl Compounds. J. Org. Chem. 1997, 62, 6974-6977.

(12) a) Muñoz III, S. B.; Daifuku, S. L.; Sears, J. D.; Baker, T. M.; Carpenter, S. H.; Brennessel, W. W.; Neidig, M. L. The NMethylpyrrolidone (NMP) Effect in Iron-Catalyzed Cross-Coupling with Simple Ferric Salts and MeMgBr. Angew. Chem. Int. Ed. 2018, 57, 6496-6500; b) Sears, J. D.; Muñoz III, S. B.; Daifuku, S. L.; Shaps, A. A.; Carpenter, S. H.; Brennessel, W. W.; Neidig, M. L. Effect of bHydrogens on Iron Speciation in Cross-Couplings with Simple Iron Salts and Alkyl Grignard Reagents. Angew. Chem. Int. Ed. 2019, 58, 2769-2773.

(13) Fürstner, A.; Martin, R.; Krause, H.; Seidel, G.; Goddard, R.; Lehmann, C. W. Preparation, Structure, and Reactivity of Nonstabilized Organoiron Compounds. Implications for IronCatalyzed Cross Coupling Reactions. J. Am. Chem. Soc. 2008, 130, 8773-8787.

(14) Bedford, R. B.; Brenner, P. B.; Carter, E.; Cogswell, P. M.; Haddow, M. F.; Harvey, J. N.; Murphy, D. M.; Nunn, J.; Woodall, C. H. TMEDA in Iron-Catalyzed Kumada Coupling: Amine Adduct versus Homoleptic "ate" Complex Formation. Angew. Chem. Int. Ed. 2014, 53, 1804-1808.

(15) Rousseau, L.; Herrero, C.; Clémancey, M.; Imberdis, A.; Blondin, G.; Lefèvre, G. Evolution of Ate-Organoiron(II) Species towards Lower Oxidation States: Role of the Steric and Electronic Factors. Chem. Eur. J. 2020, 26, 2417-2428.

(16) Casitas, A.; Krause, H.; Goddard, R.; Fürstner, A. Elementary Steps of Iron Catalysis: Exploring the Links between Iron Alkyl and Iron Olefin Complexes for their Relevance in C-H Activation and C-C Bond Formation. Angew. Chem. Int. Ed. 2015, 54, 1521-1526.

(17) Cahiez, G.; Lefèvre, G.; Moyeux, A.; Guerret, O.; Gayon, E.; Guillonneau, L.; Lefèvre, N.; Gu, Q.; Zhou, E. Gram-scale, Cheap, and Eco-friendly Iron-catalyzed Cross-Coupling between Alkyl Grignard reagents and Alkenyl or Aryl halides. Org. Lett. 2019, 21, 2679-2683. (18) Fleischauer, V. E.; Muñoz III, S. B.; Neate, P. G. N.; Brennessel, W. W.; Neidig, M. L. NHC and Nucleophile Chelation Effects on Reactive iron(II) Species in Alkyl-Alkyl Cross-Coupling. Chem. Sci. 2018, 9, 1878-1891.

(19) Watson, S. C.; Eastham, J. F. Colored Indicators for Simple Direct titration of Magnesium and Lithium reagents. J. Organomet. Chem. 1967, 9, 165-168. 


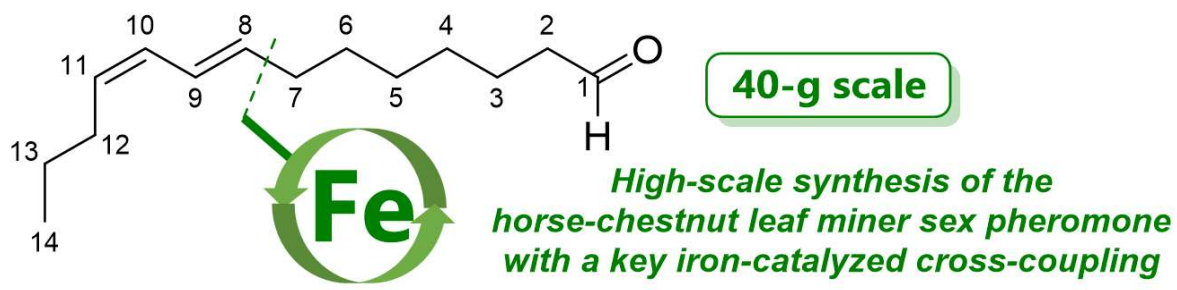

